This item was submitted to Loughborough's Research Repository by the author.

Items in Figshare are protected by copyright, with all rights reserved, unless otherwise indicated.

\title{
Human exposure to antimicrobial resistance from poultry production: assessing hygiene and waste-disposal practices in Bangladesh
}

\section{PLEASE CITE THE PUBLISHED VERSION}

https://doi.org/10.1016/j.ijheh.2019.07.007

\section{PUBLISHER}

Elsevier

\section{VERSION}

AM (Accepted Manuscript)

\section{PUBLISHER STATEMENT}

This paper was accepted for publication in the journal International Journal of Hygiene and Environmental Health and the definitive published version is available at https://doi.org/10.1016/j.ijheh.2019.07.007

\section{LICENCE}

CC BY-NC-ND 4.0

\section{REPOSITORY RECORD}

Alam, Mahbub-UI, Mahbubur Rahman, Abdullah-Al Masud, Mohammad Aminul Islam, Muhammad Asaduzzaman, Supta Sarker, Emily K. Rousham, and Leanne Unicomb. 2019. "Human Exposure to Antimicrobial Resistance from Poultry Production: Assessing Hygiene and Waste-disposal Practices in Bangladesh". figshare. https://hdl.handle.net/2134/38343. 
Human exposure to antimicrobial resistance from poultry production: assessing hygiene and waste-disposal practices in Bangladesh

Authors: Mahbub-Ul Alam ${ }^{1}$, Mahbubur Rahman ${ }^{* 1}$, Abdullah-Al-Masud ${ }^{1}$, Mohammad Aminul Islam $^{2,3}$, Muhammad Asaduzzaman ${ }^{2,4}$, Supta Sarker ${ }^{1}$, Emily Rousham ${ }^{5}$, Leanne Unicomb ${ }^{1}$

1 Environmental Interventions Unit, Infectious Disease Division, icddr,b, Bangladesh

2 Laboratory Sciences and Services Division, icddr,b, Bangladesh

3 Paul G. Allen School for Global Animal Health, Washington State University, USA

4 Centre for Global Health, University of Oslo, Norway

5 School of Sport, Exercise and Health Sciences, Loughborough University, UK

Corresponding author: Mahbub-Ul Alam, Environmental Interventions Unit, Infectious Disease Division, icddr,b, 68, Shaheed Tajuddin Ahmed Sarani, Dhaka-1212, Bangladesh; mahbubalam@,icddrb.org

* Contributed equally to the first author

Main text word count: 5,181 words 


\section{Abstract (404 words):}

The unregulated use of antibiotics is linked with intensive poultry farming in developing economies. In low-and middle-income countries, the dissemination of antimicrobial resistance (AMR) has also been attributed to contamination, poor public health infrastructure and inadequate waste disposal practices. There are limited data on hygiene and waste disposal practices in small-scale commercial and household poultry farming and market sales in Bangladesh. Our objective was to explore human exposures, hygiene and waste disposal practices in poultry raising and processing to identify probable pathways for transmission of AMR bacteria.

We employed mixed methods approaches of in-depth interviews and structured observations to assess exposures, hygiene behaviours and waste-disposal practices relating to poultry production in Bangladesh. Interviews $(\mathrm{n}=18)$ were conducted with commercial poultry farmers, backyard poultry owners, and live poultry market workers. Structured observations were conducted for six-hours in five households, five commercial farms and five urban live bird markets to assess the frequency of transmission/ exposure events in these settings.

Interviews highlighted existing practices that can contribute to transmission of antimicrobial resistant bacteria from poultry to humans. In households and farms, untreated poultry waste and carcasses were disposed of on agricultural fields and in water bodies which may contaminate surface water and soil with poultry faeces. Biosecurity precautions were not used, and hands were rarely washed with soap after handling poultry. In urban markets, live poultry slaughter and processing was done on site with bare hands which were subsequently rinsed in water stored in containers without soap. Solid waste from poultry processing was disposed into municipal waste disposal stations and liquid waste was discarded into open drains.

Structured observations revealed that workers in live poultry markets had the highest direct contact with poultry and poultry waste, almost tenfold higher than those working in poultry farms or with domestic poultry (59 vs 544 observed direct poultry exposure events) placing them at particularly high risk of exposure to faecal bacteria. Biosecurity measures were limited; in some cases, workers in commercial farms and urban markets had gloves and masks but often did not use them. In $88 \%(606 / 689)$ of exposure events no handwashing took place. Eating and 
drinking after handling poultry and without washing hands was observed in all three settings. These data suggest effective intervention strategies to reduce environmental contamination and to decrease risks of transmission should be prioritized. Data on prevalence of risk behaviours and AMR transmission to humans along environmental pathways can inform policy and intervention strategies. 


\section{Background}

The requirement for animal-sourced protein for human consumption is increasing globally at an unprecedented rate (Van Boeckel et al., 2015). To meet this demand, production techniques for livestock and poultry rearing strives for increasing cost-effectiveness (Silva et al., 2013; Zhu et al., 2013). In Bangladesh, the poultry sector accounts for $14 \%$ of the total value of livestock output. Poultry meat alone contributes $37 \%$ of the total meat production in Bangladesh (World's Poultry Science Association, 2017). An estimated 150,000 poultry farms in Bangladesh produce 570 million tones of meat and 7 billion eggs per year (Ansarey, 2012) for domestic consumption. At least 6 million people are involved in the industry (Ansarey, 2012; Raha, 2000), many of whom work in small-scale production where regulations around biosecurity are not enforced and consequently they have direct exposure to poultry and poultry waste.

Antibiotics and other drugs are used to treat poultry diseases and as growth promoters during production (Marshall \& Levy, 2011). Antimicrobial resistant (AMR) bacteria can be transmitted to humans through ingestion of contaminated food (Price, Johnson, Vailes, \& Silbergeld, 2005; Van Boeckel et al., 2015; Verraes et al., 2013), or via the contaminated environment- i.e. through water, soil, air (Graham, Evans, Price, \& Silbergeld, 2009) and through direct contact with livestock (Smith et al., 2013). Farm and slaughterhouse workers, veterinarians, those with close contact to animals consuming antibiotics are directly at risk of exposure to resistant bacteria (Marshall \& Levy, 2011). Although antibiotic use in animals and poultry may correspond to a risk to human health, the level and comparative impact of this route of transmission has not been well investigated (Hudson et al., 2016).

The patterns of antimicrobial administration and consumption in low- or middle-income (LMICs) and high-income countries differ in many regards, mostly due to the absence of specific and authorized legislative framework of the animals for food production or weak enforcement of laws in the former. The estimated global average annual consumption of antimicrobials per kilogram of animal produced was $148 \mathrm{mg} \cdot \mathrm{kg}^{-1}$ for chicken, which is estimated to increase by $67 \%$ (105,596 $\pm 3,605$ tons) by 2030 (Van Boeckel et al., 2015). Up to a third of the increase in consumption is attributed to shifting production practices in middle-income countries where extensive farming systems will be replaced by large scale intensive farming operations that routinely use antimicrobials in subtherapeutic doses (Van Boeckel et al., 2015). Bangladesh aims 
to increase the per capita consumption of eggs to 85/year from 51 at present, and the per capita meat consumption to 7.5 kilograms a year from 4.2 kilograms (World's Poultry Science Association, 2017). As a result, inappropriate and irrational use of antimicrobials may increase in LMICs like Bangladesh (Parvez et al., 2018; Van Boeckel et al., 2015).

Poultry have been shown to carry resistant bacteria, both from farms (Braykov et al., 2016; Brower et al., 2017) and household rearing (Braykov et al., 2016). In Bangladesh, of 279 dead or sick poultry, more than $55 \%$ of pathogenic $E$. coli were resistant to at least one or more of the tested antibiotics, and $37 \%$ of the isolates showed multiple-antibioticresistance phenotypes. The most common resistances observed were against tetracycline (46\%), trimethoprim-sulphamethoxazole (27\%), nalidixic acid (26\%), ampicillin (26\%), and streptomycin (21\%) (Hasan et al., 2011). However, we have limited knowledge about antibiotic use for animal rearing in LMICs and the types of exposures that take place in animal-food production in these settings (Landers, Cohen, Wittum, \& Larson, 2012). The indiscriminate use of antibiotics, along with poor biosecurity and waste management systems, in livestock and poultry production may create a reservoir of resistant bacteria with onward transmission to humans.

In Bangladesh, limited data exist on how backyard and farm-based hygiene and waste disposal behaviours can contribute to transmission of antibiotic-resistant bacteria (Landers et al., 2012). This study was designed to examine potential transmission routes of AMR bacteria from animals to humans either i) directly through contact with food-producing animals or ii) indirectly through the disposal of animal waste directly into the environment (soil, solid waste, wastewater or surface waters) that could lead to subsequent exposure of humans via contaminated environments. Qualitative and quantitative insights into types of exposure and behaviours contributing to transmission can inform interventions to reduce AMR bacterial infections among high risk groups.

Our objective was to identify human behaviours that contribute to human and environmental exposure to AMR bacteria from food-producing animals, focusing on poultry. We hypothesized that the types of exposure would vary by setting (rural households, commercial farms and urban markets), and that commercial poultry farmers and market poultry sellers would have greater risk of AMR bacterial acquisition through more frequent direct exposures to poultry 
and poultry waste. To this end we assessed hygiene and handwashing behaviours, waste management practices and biosecurity relating to domestic and small to medium scale commercial poultry production systems. A further aim was to apply novel methods to understand exposures and transmission of AMR using structured observations and in-depth interviews.

\section{Methods}

To determine poultry raising practices, poultry handling and waste disposal practices, we selected three groups with differing human-poultry interactions in order to assess the potential routes of AMR bacteria transmission in each setting: 1) rural villages where they use traditional animal husbandry, who usually raise less than 20 poultry (Chowdhury, 2013), 2) small and medium-size commercial poultry farms in peri-urban sites around Dhaka (small farms typically have 500-1000 poultry; medium farms 1,000-2,000 poultry), 3) urban live poultry markets in high-density residential areas of urban Dhaka.

We used exploratory qualitative methods and quantitative structured observations to understand behaviors that create the opportunity for exposures to AMR bacteria. We selected 8 rural households from 8 villages in Mirzapur sub-district where the poultry industry constitutes a significant part of the local economy. We selected 3 households for in-depth interviews (IDIs), 5 households for structured observations (SOs), 15 commercial farms from 10 villages from Mirzapur sub-district (10 for IDIs and 5 for SOs), and 5 live bird markets from the closest urban center, Dhaka (5 IDIs and 5 SOs).

In-depth interviews

We used purposive sampling to enroll participants for IDIs and SOs. In detail; we purposively selected households to ensure variation in economic status and with different chicken flock sizes. For IDIs, among the eight rural villages in Mirzapur sub-district, we enrolled three women (one from each of three villages) having a child less than five years old; these women owned backyard poultry and were responsible to care for them. We selected these households from three different villages to capture a wide range of practices within this small study. We targeted households with a children less than five years of age, the most vulnerable group for infectious disease, to capture child-poultry interactions. From a list of poultry farms in Mirzapur sub-district provided by the local livestock office, we purposively selected ten small- 
medium commercial poultry farms and approached owners or poultry workers for IDIs. Again, we purposively selected farms with different flock sizes. We selected five different live bird markets within Dhaka city that were from distant parts of the city and selected four live poultry sellers (each from a different market) and one waste collector for IDIs.

During interviews, we asked the respondent about using personal protective equipment (i. e. use of gloves, mask) and hygiene practices during poultry handling, feeding and slaughtering or cleaning poultry sheds. Further topics explored included the use of equipment such as a local agricultural hoe, broom for waste disposal and cleaning; hygiene practices such as handwashing with soap, poultry rearing practices around knowledge, use and source of medicine (including antibiotics) for treating ill poultry.

Interviews were audio-recorded, and all narrative data were analyzed manually after transcription and translation by experienced anthropologists. We followed thematic analysis process for qualitative data.

Structured observations

This is a method of observing frequencies of actual behaviors without direct involvement with the participants (Luby, Halder, Huda, Unicomb, \& Johnston, 2011; Parvez et al., 2018; Ram et al., 2010; Wichaidit et al., 2016). Structured observations have been employed in previous behavioural studies and intervention assessment to understand handwashing behaviours (Halder et al., 2010; Ram et al., 2010) and risk of pathogen transmission in food preparation (Luby et al., 2011; Parvez et al., 2018). The starting point of the observation was an 'exposure' event, in this case involving direct human contact with poultry (i.e. feeding or administering medicine, handling poultry, cleaning their environment) or poultry-products (eggs, poultry litter/faeces). For a given exposure event, we followed the activity to observe potential for onward transmission of bacteria from poultry to humans namely i) whether handwashing, where at least the palms were rubbed, with or without soap took place after the exposure event or whether hands were rinsed whereby participants poured a small amount of water onto the hands or just dipping hands into a bucket of water, and ii) whether eating, drinking, food preparation or feeding children took place after the exposure event. A paper-based structured observation tool was developed, based on modified versions of previously employed SO tools (Alam et al., 2017; 
Unicomb et al., 2018). The structured observation tool listed pre-defined activities relating to exposure and transmission events as listed above.

We conducted SO in the households/farms where we did not conduct IDIs. From a list of poultry farms in Mirzapur sub-district provided by the local livestock office, we selected five small-medium commercial poultry farms for SO. We conducted SO in five distinct markets in urban Dhaka where we also conducted IDIs with only one seller from each market. We conducted two sessions of SO per household/farm/market, each of three hours duration. We conducted SOs in 2 sessions of 3-hours for each of the five households from five rural villages which were not included in the IDIs.

Data collection was performed by trained female observers in households and by male observers in commercial poultry farms and urban live birds markets during March-May 2017. We conducted the two SO sessions per household in the same day from three potential slots: early morning (around 6:00 am to 9:00 am), afternoon (around 12:00 pm to 3:00 pm), and evening (around 3:00 pm to 6:00 pm) to capture poultry nurturing in three different times of the day.

All data from structured observations were then entered into Excel and analyzed using STATA (version 13) and stored in data repository (Rousham et al., 2018). Each observed exposure and hand washing opportunity was considered as a separate event during analysis. We reported each activity during the observation period as exposure event and reported percentage of hygiene practice before/after the exposure event.

\section{Results}

\section{Backyard poultry}

Respondents were all female, aged 21 to 40 years and had been rearing poultry for the last 4 to 30 years. Poultry, especially chickens were predominantly reared for eggs and occasionally for meat. Chickens were not kept in pens or sheds during the day but roamed around the households and courtyards. Participants, when asked whether they handled poultry during day to day care reported that usually direct poultry handling was only required when slaughtering or separating ill birds from the rest of the flock. They reported that they usually kept the sick poultry separately and if they did not recover, they were slaughtered for consumption or 
sold at the local market or to neighbors. They unlocked poultry pens early in the morning and collected the eggs with bare hands. After collecting eggs, they washed them with water before storing.

All household backyard poultry owners reported that they cleaned poultry pens once or twice a month. They commonly used a spade (locally called 'pachon'), a wooden scoop called 'harpat' and a broom to clean the poultry pen but did not use water or a cleaning agent. They reported that they did not use any personal protective equipment (e.g., gloves, mask, or boots) and usually cleaned poultry pens just before taking a bath. Therefore, handwashing with soap was not done. They perceived that personal protective equipment were not needed during handling poultry and cleaning poultry pens.

Rural poultry owners slaughtered poultry with a knife and used bare hands. They usually slaughtered poultry on the platform around the tubewell water supply which drained into a nearby ditch through a narrow drainpipe. After slaughtering, they washed away the poultry blood with water. The offal, feathers and residual parts of the bird were usually disposed into the nearby pit beside their house, where other household waste was generally disposed. They usually disposed poultry litter after cleaning poultry pen or courtyard in the nearby vegetable garden as fertilizer. One respondent mentioned:

"We disposed the poultry litter, offal, feathers and residual parts of the poultry in that ditch (indicating nearby ditch beside household) and we do not use the water from that ditch." (Backyard poultry raiser, aged 27, IDI-TR8001).

The most commonly observed activities leading to exposure were feeding poultry ( $44 \%$ of exposure events); handling healthy poultry (13\%), cleaning poultry pens (12\%) and collecting eggs $(10 \%)$. All except feeding the poultry involved direct contact with poultry, poultry products or poultry waste.

Backyard poultry raisers reported that handwashing was usually done while rinsing eggs by water. Handwashing either with soap and water, or just water, was largely subject to the type of subsequent activities of poultry raising and cleaning. Participants reported that they washed hands with soap after contact with poultry if they subsequently prepared food or ate. During SO, 
we rarely ( $20 \%$ of observations) found soap and water together at convenient locations (Table 1$)$. Usually, soap was stored inside the house and used during bathing.

During SO, participants commonly touched their face (13\%), ate food (33\%) and betel leaf (27\%), prepared food, and fed children without washing hands with soap (7\%) after handling any tools or items involved in poultry nurturing (Table 1). Most of the caregivers rinsed hands with water only after being exposed to other poultry caring events (e.g. after touching or unlocking poultry pen, touching feeding pot, touching eggs). We did not observe any handwashing with soap ( 0 of 15 events) before food preparation or eating, and only once after handling poultry ( 1 of 59 events) (Table 1). We observed that poultry faeces were collected from the poultry pens and then usually disposed into a ditch or refuse pit located next to households (Table 1).

\section{Commercial poultry farms}

The poultry workers reported that they were involved in this business from one to 24 years. Of the ten farms included in the study, the number of chickens per farm ranged from 500 to 1300 and the respondents were between 20 and 47 years of age. Only one out of the ten respondents was female. Two respondents had completed higher secondary education, four completed secondary education, three had completed primary education, and one had no formal education.

All poultry farms had rudimentary poultry housing structures made of tin with bamboo or mud floors which were covered with rice bran as bedding. Half of the metal fence was fixed with chicken wire for ventilation. A plastic cover on top of the chicken wire, could be folded up or down for protection. Sheds were cleaned after a flock was sold after 30 days of rearing. As all the farms were located on land next to the owner's household, the owner himself and his family members looked after the poultry.

All respondents reported that as farm owners, they had previously bought handgloves and masks for use at work. Protective equipment like masks and handgloves were used initially, but due to discomfort in the hot, humid climate they stopped after a few days of use. They reported that gloves were not suitable for working swiftly. One farm worker mentioned: 
"We do not use mask, gloves due to discomfort and inconvenience. If we use masks and gloves, we could not work swiftly." (Poultry Farm worker, aged 26, IDI-TF3003).

During interviews, almost all participants reported that they wore separate sandals inside poultry pens, but during structured observations, we rarely observed farm workers using separate sandals. The workers perceived that they should use personal protective equipment i.e. hand gloves, masks and separate sandals when working inside poultry pens.

Poultry litter and leftover feed was usually disposed into the agricultural fields, open refuse pits or open drains. Between each flock, litter from beds was sold to local farmers for use as fertilizer. Poultry carcasses were commonly disposed beside the poultry sheds where dogs or foxes usually scavenged for food. Sick or diseased birds were separated from the flock or slaughtered. One poultry farm owner mentioned:

"Sometimes I slaughter a diseased bird and consume. If the bird dies, I throw it in the nearby ditch. Dogs and foxes usually take the dead bird." (Poultry Farm owner, aged 46, IDITF3001).

The most commonly observed activities leading to exposure were feeding poultry ( $29 \%$ of exposure events), handling healthy poultry (19\%), cleaning poultry cages (17\%) and handling or disposal of solid waste (17\%). All except feeding involved direct contact with poultry or poultry waste. During SO, the use of biosecurity equipment was minimal (only 13\% respondents used gumboots) this was supported by reported behavior in IDIs. In less than half of cases, soap was observed at a nearby location (40\%) and handwashing with soap before eating was uncommon, among only $8 \%$ after handling poultry (on 2 occasions out of 26 opportunities). Handwashing with soap was rare after handling poultry, at less than $1 \%(1 / 86)$. Poultry faeces, litter and waste products (offal, dead poultry) were usually observed dumped openly into the agricultural fields, water bodies or ditches. Farm workers were observed to frequently touch their face and perform additional tasks subsequent to the poultry handling without handwashing with soap. This occurred in $65 \%$ of observed occasions (Table 1).

\section{Urban live bird markets}

Workers from urban live bird markets had been in the trade from 5 to 30 years and their age was between 23 and 45 years all being male. Among them, two had no formal education, two completed primary education and one completed high school education. 
Most of the live bird stalls were located at the corner of the local bazaar (market), where vegetables and other grocery items were also sold. The market stalls included in the study sold broiler, layer and backyard poultry only. These poultry stalls are usually in covered areas of markets. The size of the stalls was very compact, usually 3 square meters where poultry were kept in different cages in front of the stalls and slaughtering took place inside the stalls. The staff slaughtered, defeathered and processed the poultry on request of the customer who waited while the process was completed. Plastic water containers at the shop were filled from municipal taps in the beginning of the day and used throughout the day for rinsing hands and knifes. The water stored in buckets or drums were observed to be turbid.

In urban live bird markets, poultry were usually kept at market stalls for a maximum of 2 days before being sold. During this time, poultry only required feeding with commercially available poultry food and were provided drinking water. Broiler slaughtering and processing, done with a knife and bare hands, was performed on, or adjacent to, the stall. In most cases, there was no designated person for each task. The shopkeeper performed all tasks from selling to slaughtering. All poultry stall staff reported that hand gloves and masks are good protective equipment, but due to high temperature $\left(\sim 35^{\circ} \mathrm{C}\right.$ for most of the year) and humidity they did not use these equipment. One live bird market worker mentioned:

"We use mask but not regularly. When there are lots of customers and we are in a hurry, we forgot to use the mask." (Urban live bird market, aged 22, DL-6601-ULBM).

Water was rarely used to clean the market stall, only used to wash the processing tables and slaughter areas throughout the day. Sellers cleaned the stall structures every night with a broom and dustpan before closing so that customers would not be disgusted by poultry residue, reported respondents. Poultry litter and residual feed were usually swept up with a broom at the end of the day. Poultry litter remained stuck in a layer on the floor but nothing further was done to clean this away.

The most commonly observed activities leading to exposure to poultry were handling healthy poultry (33\% of exposure events), slaughtering poultry (21\%) and processing poultry carcasses (21\%), all of which led to direct contact with blood, meat and faecal material. Participants were asked when they wash hands and they reported that they used soap for 
handwashing before eating. If they were required to wash hands during working hours, they used only water. They considered hand rinsing or dipping into a bucket of water as handwashing (carried out in $8 \%$ of total 544 exposure events). Poultry workers reported that they sometimes wiped their hands with a cloth after slaughtering a few chickens rather than washing hands. Handwashing with soap was rarely detected/described both during SO $(0.2 \%, 1 / 544)$ and IDI. Of the observed eating or drinking events that took place among the market workers none washed hands beforehand (0/106 events).

Poultry sellers collected drinking water from water vendors who moved through the market. Respondesnt reported that, inside the vending stalls staff generally avoid eating or drinking, but if required they used polythene bags as hand gloves before touching food.

Shopkeepers stored offal and residual parts of poultry, excluding feathers, in a drum which was sold to other vendors who bought and sold these to fish farmers for use as feed for African catfish and other farmed fish, such as Climbing perch (Koi) and Tilapia (Telapia). Poultry faeces, feathers and other solid poultry waste were disposed in the street bin where municipal waste disposal stations were located near the market. Waste collectors in the urban live bird market disposed of waste into the municipal dustbin located near the market and they reported that they do not use masks, hand gloves, boots, or plastic coats for their personal safety due to discomfort.

"We are told to use hand gloves, mask, boots, etc., but these are not comfortable for working. We can't swiftly work with these. Besides, our employers are not willing to spend money for this. We are now accustomed with this condition." (Waste collector, aged 29, IDI-DL 6901)

At one market the disposal of offal and residual poultry parts differed. Poultry vendors stored offal in drums, which was then collected by the waste collectors and disposed in the municipal corporation dustbin located on the street and cleaners from the municipal corporation then separated offal from other waste. Fish farmers collected offal from municipal cleaners and gave a payment and they in turn provided an allowance to the poultry sellers once or twice a year. Other poultry parts such as the livers, skin and chicken feet were purchased by other low-income community members directly from the stalls. 


\section{Discussion}

Rural poultry owners, workers in small to medium scale commercial poultry farms, and workers and waste collectors in urban live bird markets demonstrated behaviours leading to direct exposure to poultry faeces through handling, slaughtering and processing without the use of protective equipment.

Our structured observation revealed that rural households had the lowest frequency of direct exposure to poultry, commercial farmers had intermediate frequency of exposure, and market live poultry sellers had the highest frequency of direct exposure to poultry through their intense daily work of slaughtering and processing live birds. This finding supports our hypothesis around predicted levels of exposure to antibiotic-resistant bacteria. Our study also shows, however, that all three settings had frequent indirect exposures to environments that had been contaminated with poultry waste and therefore likely AMR bacteria because of the closely shared environments of humans and poultry.

Waste handling procedures in poultry farming require immediate attention. Waste collectors, cleaners, farm workers as well as backyard poultry raisers handled poultry waste with bare hands. Disposal of poultry waste into water bodies or agricultural fields leads to contamination of surface water and soil with poultry faeces (Joardar \& Rahman, 2018). Poultry feces frequently contain AMR bacteria that can contaminate the environment (Price et al., 2005). Studies from LMICs have shown that commercial poultry farm workers are at higher risk than the population who are not involved in poultry keeping (Donkor, Newman, \& Yeboah-Manu, 2012; Raghunath, 2008). In our study, we found family members are also involved in taking care of poultry in commercial farms.

In rural households the courtyards were routinely contaminated with poultry faeces from free-ranging poultry (Roess et al., 2015; Shanta et al., 2017). These compound areas are also used for food preparation, child play activities and areas for washing and drying utensils and cloths. Among households who raised poultry, 37\% reported that children touched, carried, or played with poultry in the past 2 weeks (Shanta et al., 2017). Internal and external compound floors were most commonly made of compacted mud/soil which has been shown to harbour high concentrations of $E$. coli (Ercumen et al., 2017). A systematic review and meta-analysis has 
shown an association between exposure to animal faeces and human diarrhea episodes (Zambrano, Levy, Menezes, \& Freeman, 2014). The association between animal faeces exposure and colonization with AMR bacteria is worth of future investigation.

In small and medium scale commercial farms, poultry farmers had indirect exposures through daily feeding and watering of the poultry and contact with poultry faeces. The highest frequency of direct exposure events occurred among market workers who handled and slaughtered live animals and their waste. Additionally they were exposed, to an environment highly contaminated with fecal bacteria derived from poultry including contaminated floors, surfaces, knives and stored water in containers that received minimal cleaning.

Handwashing with soap after poultry handling was rarely observed in all three settings; market sellers and farm workers wiped hands with a cloth, which had been used repeatedly, frequently touching their faces during the process. A nationally representative survey conducted among Bangladeshi primary backyard poultry raisers reported that $85 \%$ never washed their hands with soap after handling poultry (Shanta et al., 2017), which is in line with our observation. Poultry farm workers who fed poultry, cleaned poultry pens, poultry feces and did not wash hands had a 7.6 times greater risk of respiratory infection compared to workers who did not perform these behaviors frequently (Nasreen et al., 2015). Our findings indicate that presence of soap and water together was very uncommon in all three settings making it difficult to wash hands with soap. A first step to increasing handwashing practices would be to conveniently locate well stocked, handwashing facilities. Approximately 6 million people in Bangladesh are working in the poultry production sector and they are at risk of frequent exposure to AMR bacteria which can be further transmitted to their family members.

During poultry slaughtering and processing, especially in the urban live bird markets, direct contact with blood, offal, raw meat and saliva put poultry raisers and slaughterers at high risk of disease transmission (Dinh et al., 2006; Peng et al., 2014; Rimi et al., 2014; Zhou et al., 2009). Additionally, no personal protection was used during feeding, handling, slaughtering poultry or cleaning poultry feces to minimize direct exposure. Respondents from poultry farms and urban live bird markets perceived that personal protective measures should be used but high temperatures and humidity caused significant discomfort and was a barrier to use. Backyard poultry raisers, however, did not think that personal protective equipment was 
necessary. Ercumen and colleagues (Ercumen et al., 2017) showed that E. coli contamination was higher in hands, drinking water containers, and compound floors even in the presence of onsite sanitation. Therefore, the lack of hygiene measures and practice of not washing hands with soap increases the chance of transmission. The potential for airborne transmission of AMR may also apply in these settings, highlighted in recent studies with higher levels of resistance detected in air surrounding livestock feeding areas (Blaak et al., 2015). Further investigation is necessary to quantify exposure and risk linked with environmental pathways of AMR bacteria in absence or presence of handwashing facilities and practices.

\section{Limitations}

Our study has several limitations. This was a small study carried out in one rural and one urban site for the purpose of obtaining formative data on current behaviours around hygiene and waste disposal practices in relation to AMR transmission routes. Despite being a small study, these observations are likely to be typical for much of the country. In addition, studies have consistently shown that self-reported data over estimate hygiene behaviours, compared with SO (Biran et al., 2008; Curtis et al., 1993; Halder et al., 2010; ManunEbo et al., 1997; Stanton, Clemens, Aziz, \& Rahman, 1987). Additionally, the presence of the observer increases handwashing behavior (Drankiewicz \& Dundes, 2003; Munger \& Harris, 1989; Ram et al., 2010), however handwashing was rare in the observed locations.

\section{Conclusion}

To our knowledge, this is the first study to use structured observations to compare relative frequency of potential AMR bacterial transmission and exposure events between humans and poultry in resource-poor settings. We have not seen any previous study that has related known animal exposures to likelihood of transmission of resistant bacteria from poultry to humans, but this is a first step in identifying the key behaviours and understanding exposures. A further strength of the study is taking a more granular approach to identify direct and indirect transmission routes of potentially resistant bacteria from poultry, which can be used to prioritize hygiene behaviours and waste disposal practices for future interventions. Future intervention design could consider the barriers to biosecurity measures, for example by improvement of working conditions under high temperature and humidity that lead to poor compliance with use of gloves and masks. 


\section{Recommendation}

The Bangladesh Fish Feed and Animal Feed Act 2010 banned use of antibiotic as growth promoter, but research revealed that antibiotics are still present in poultry meat and eggs (Hasan et al., 2011). A report argues that corruption levels in countries are strongly correlated with high levels of antimicrobial resistance (Collignon, Beggs, Walsh, Gandra, \& Laxminarayan, 2018). Tighter regulation around the limited use of antibiotics as growth promoter is needed. There is also a need for effective policy and recommendations on the use of poultry litter and poultry residuals as fertilizer and fish feed to minimize the potential spread of AMR bacteria in the environment and in aquaculture. To formulate effective intervention strategies to prevent infections caused by AMR bacteria, it is important to distinguish which fraction of the total disease burden and cost are attributable by different sources of resistant bacteria, including animal husbandry, food animal or the environment (Costa, Vaz-Pires, \& Bernardo, 2008; Fair \& Tor, 2014; Woolhouse, Waugh, Perry, \& Nair, 2016).

Recent research using population data on antibiotic resistant bacteria in LMICs suggests that water, sanitation and hygiene (WaSH) and exposure to contaminated environments may play an important role in transmission (Graham et al., 2018). One study suggests population exposures or 'contagion', public health infrastructure and governance may be as important as direct use of antibiotics in contributing to the global prevalence of AMR (Collignon et al., 2018). Finer-grained studies assessing transmission risk for those with high environmental exposures are needed (Trust, CDC, \& Network, 2018).

\section{Acknowledgement}

This work was supported by the Antimicrobial Resistance Cross Council Initiative supported by the seven research councils in partnership with the Department of Health and Department for Environment Food \& Rural Affairs (Award number: NE/N019555/1). icddr,b is thankful to the Governments of Bangladesh, Canada, Sweden and the UK for providing core/unrestricted support. Authors would like to thank participants and data collectors of the study.

\section{Author's contribution}


Mahbub-U1 Alam, MPH, Mahbubur Rahman, MSPH, Abdullah-Al-Masud, MPH, Mohammad Aminul Islam, PhD, Md. Muhammad Asaduzzaman, MPhil, Supta Sarker, MSc, Emily Rousham, $\mathrm{PhD}$, Leanne Unicomb, $\mathrm{PhD}$

Contributors: ER, MAI, and LU conceived and designed the original protocol. All authors were involved in designing the data collection instrument, and selection of field sites. Data entry, cleaning and analysis was carried out by AAM, SS, and MA. ER, LU, and MAI provided advice on data interpretation and analysis. MA wrote the first draft of the manuscript with LU and MR. All authors contributed to subsequent and final drafts. 
Table 1: Structured observations ( $2 * 3$ hour duration) in 5 households, 5 commercial farms and 5 urban live bird markets

\begin{tabular}{|c|c|c|c|c|}
\hline Indicator & $\begin{array}{l}\text { Household } \\
\mathrm{n} / \mathrm{N}(\%)\end{array}$ & $\begin{array}{l}\text { Farm } \\
\mathrm{n} / \mathrm{N}(\%)\end{array}$ & $\begin{array}{l}\text { Market } \\
\mathrm{n} / \mathrm{N}(\%)\end{array}$ & $\begin{array}{l}\text { Overall } \\
\mathrm{n} / \mathrm{N}(\%)\end{array}$ \\
\hline \multicolumn{5}{|l|}{$\begin{array}{l}\text { Availability of handwashing materials near } \\
\text { poultry shed: }\end{array}$} \\
\hline Presence of soap & $1 / 5(20)$ & $2 / 5(40)$ & $1 / 5(20)$ & $4 / 15(27)$ \\
\hline Presence of water & $4 / 5(80)$ & $5 / 5(100)$ & $4 / 5(80)$ & $13 / 15(87)$ \\
\hline Presence of cloth for drying hands & $1 / 5(20)$ & $0 / 5(0)$ & $3 / 5(60)$ & $4 / 15(27)$ \\
\hline $\begin{array}{l}\text { Distance (metres) to handwashing site } \\
\text { (mean, SD) }\end{array}$ & $7.3(6.7)$ & $11.2(9.1)$ & $3.7(4.3)$ & - \\
\hline \multicolumn{5}{|l|}{ Number of observed exposure events: } \\
\hline Any exposure events with poultry & 59 & 86 & 544 & 689 \\
\hline $\begin{array}{l}\text { Drinking and eating events after exposure } \\
\text { with poultry }\end{array}$ & 15 & 26 & 106 & 147 \\
\hline Waste handling/disposal events & 6 & 23 & 19 & 48 \\
\hline Appliance cleaning events & 5 & 14 & 14 & 33 \\
\hline \multicolumn{5}{|l|}{ Observed poultry exposure events: } \\
\hline Feeding poultry & $26 / 59(44)$ & $25 / 86(29)$ & $39 / 544(7)$ & - \\
\hline Handling healthy poultry & $8 / 59(13)$ & $16 / 86(19)$ & $182 / 544(33)$ & - \\
\hline Cleaning poultry nest/bedding/Case & $7 / 59(12)$ & $15 / 86(17)$ & $6 / 544(1)$ & - \\
\hline Processing poultry & $1 / 59(2)$ & - & $112 / 544(21)$ & - \\
\hline Collecting eggs & $6 / 59(10)$ & $0 / 86(0)$ & $1 / 544(0)$ & - \\
\hline Handling or disposal of solid waste & $4 / 59(7)$ & $15 / 86(17)$ & $12 / 544(2)$ & - \\
\hline Handling or disposal of liquid waste & $2 / 59(3)$ & - & $3 / 544(1)$ & - \\
\hline Handling sick ${ }^{1} / 111 /$ dead poultry & $0 / 59(0)$ & $8 / 86(9)$ & $3 / 544(1)$ & - \\
\hline Touching soil in backyard & $2 / 59(3)$ & $1 / 86(0)$ & - & - \\
\hline Administering medicine & $0 / 59(0)$ & $6 / 86(6)$ & - & - \\
\hline Slaughtering poultry & $0 / 59(0)$ & - & $114 / 544(21)$ & - \\
\hline Taking/giving money & - & - & $68 / 544(13)$ & - \\
\hline Handling offal & - & - & $4 / 544(1)$ & - \\
\hline Disposal of offal & - & - & $0 / 544(0)$ & - \\
\hline Poultry contact with human food & $3 / 59(5)$ & - & - & - \\
\hline $\begin{array}{l}\text { Total poultry exposure events in } 30 \text { hours of } \\
\text { observation }\left(5^{*} 6 \mathrm{hr} \text { observations }\right)\end{array}$ & 59 & 86 & 544 & 689 \\
\hline \multicolumn{5}{|l|}{$\begin{array}{l}\text { Number of occasions when hand washing was } \\
\text { observed after the exposure events above: }\end{array}$} \\
\hline With any soap & $1 / 59(2)$ & $1 / 86(1)$ & $1 / 544(0.2)$ & - \\
\hline With running water & $3 / 59(5)$ & $4 / 86(5)$ & $13 / 544(2)$ & - \\
\hline With water stored in a bucket & $3 / 59(5)$ & $0 / 86(0)$ & $10 / 544(2)$ & - \\
\hline Rinsing ${ }^{2}$ hand(s) with water & $2 / 59(3)$ & $0 / 86(0)$ & $45 / 544(8)$ & - \\
\hline No hand washing & $50 / 59(85)$ & $81 / 86(94)$ & $475 / 544(87)$ & $606 / 689(88)$ \\
\hline
\end{tabular}

1 "Sick poultry was identified when the poultry was not moving with the group and sitting idle. However, we confirmed with household members about the sickness of the poultry." 


\begin{tabular}{|c|c|c|c|c|}
\hline \multicolumn{5}{|l|}{$\begin{array}{l}\text { Number of occasions when protective items were } \\
\text { used out of total number of poultry exposure } \\
\text { events: }\end{array}$} \\
\hline Gumboots & - & $11 / 86(13)$ & $0 / 544(0)$ & - \\
\hline Mask & - & $0 / 86(0)$ & $48 / 544(9)$ & - \\
\hline Gloves & - & $0 / 86(0)$ & $0 / 544(0)$ & - \\
\hline Apron & - & $0 / 86(0)$ & $0 / 544(0)$ & - \\
\hline Towel/cloth & - & $0 / 86(0)$ & $0 / 544(0)$ & - \\
\hline No protective items used & - & $75 / 86(87)$ & $496 / 544(91)$ & $571 / 630(91)$ \\
\hline $\begin{array}{l}\text { Number of drinking or eating events taking place } \\
\text { after exposure to poultry or poultry products: }\end{array}$ & $15 / 59(25)$ & $26 / 86(30)$ & $106 / 544(20)$ & $147 / 689(21)$ \\
\hline Drinking water & $1 / 15(7)$ & $2 / 26(8)$ & $3 / 106(3)$ & - \\
\hline Drinking tea & $0 / 15(0)$ & $1 / 26(4)$ & $9 / 106(8)$ & - \\
\hline Eating food & $5 / 15(33)$ & $3 / 26(12)$ & $9 / 106(8)$ & - \\
\hline Smoking & $0 / 15(0)$ & $3 / 26(12)$ & $5 / 106(5)$ & - \\
\hline Eating betel leaf (paan) & $4 / 15(27)$ & $0 / 26(0)$ & $70 / 106(64)$ & - \\
\hline Touching face & $2 / 15(13)$ & $17 / 26(65)$ & $10 / 106(9)$ & - \\
\hline Handling food & $2 / 15(13)$ & - & - & - \\
\hline Feeding child & $1 / 15(7)$ & - & - & - \\
\hline $\begin{array}{l}\text { Total drinking or eating events in } 30 \text { hours } \\
\text { of observation }(5 * 6 \mathrm{hr} \text { observations })\end{array}$ & 15 & 26 & 106 & 147 \\
\hline \multicolumn{5}{|l|}{ Observed hand washing before above events: } \\
\hline With soap & $0 / 15(00)$ & $2 / 26(7.6)$ & $0 / 106(0)$ & - \\
\hline With water only & $8 / 15(53)$ & $0 / 26(0)$ & $0 / 106(0)$ & - \\
\hline No hand washing & $7 / 15(47)$ & $09 / 26(35)$ & $106 / 106(100)$ & $122 / 147(83)$ \\
\hline Not observed & - & $15 / 26(58)$ & - & \\
\hline \multicolumn{5}{|l|}{ Waste disposal locations: } \\
\hline Ground/refuse pit & $5 / 6(83)$ & $12 / 23(52)$ & $5 / 19(26)$ & - \\
\hline Litter on field/ground & $0 / 6(0)$ & $4 / 23(17)$ & - & - \\
\hline Open drain & $0 / 6(0)$ & $3 / 23(13)$ & $1 / 19(5)$ & - \\
\hline Not disposed & - & $2 / 23(8)$ & $0 / 19(0)$ & - \\
\hline Ditch & $1 / 6(17)$ & $1 / 23(4)$ & - & - \\
\hline Pond & $0 / 6(0)$ & $1 / 23(4)$ & - & - \\
\hline River/lake & $0 / 6(0)$ & $0 / 23(0)$ & - & - \\
\hline Passageway (walkway) & - & - & $7 / 19(37)$ & - \\
\hline Municipal waste bin & - & - & $2 / 19(11)$ & - \\
\hline Sold & - & - & $0 / 19(0)$ & - \\
\hline Not seen & - & $0 / 23(0)$ & $4 / 19(21)$ & - \\
\hline \multicolumn{5}{|l|}{ Appliance cleaned (when observed used): } \\
\hline Water feeder & - & $14 / 14(100)$ & - & - \\
\hline Knife & - & - & $8 / 16(50)$ & - \\
\hline Floor & - & $0 / 14(00)$ & $3 / 16(19)$ & - \\
\hline Work surface & - & - & $3 / 16(19)$ & - \\
\hline Tray & - & - & $2 / 16(13)$ & - \\
\hline Cage & - & - & $0 / 16(0)$ & - \\
\hline Feed container & $2 / 5(40)$ & $0 / 14(0)$ & - & - \\
\hline Other & $1 / 5(20)$ & $0 / 14(0)$ & $0 / 16(0)$ & - \\
\hline \multicolumn{5}{|l|}{ Appliance cleaned with: } \\
\hline Water only & $3 / 5(60)$ & $14 / 14(100)$ & $12 / 16(75)$ & - \\
\hline Water and soap & $2 / 5(40)$ & $0 / 14(0)$ & $0 / 16(0)$ & - \\
\hline Detergent & - & $0 / 14(0)$ & $0 / 16(0)$ & - \\
\hline Could not observe & - & $0 / 14(0)$ & $4 / 16(25)$ & - \\
\hline Bleach & - & $0 / 14(0)$ & & - \\
\hline
\end{tabular}

Appliance cleaned using: 
Cloth

Running water

Broom

Scrubbing brush

Hands only

Could not observe

\begin{tabular}{clll}
$0 / 5(0)$ & $5 / 14(36)$ & $1 / 16(6)$ & - \\
- & $5 / 14(36)$ & $5 / 16(31)$ & - \\
$1 / 5(20)$ & $0 / 14(0)$ & $2 / 16(13)$ & - \\
$1 / 5(20)$ & $2 / 14(14)$ & $0 / 16(0)$ & - \\
- & $2 / 14(14)$ & $1 / 16(6)$ & - \\
$3 / 5(60)$ & $0 / 14(0)$ & $7 / 16(44)$ & - \\
\hline
\end{tabular}




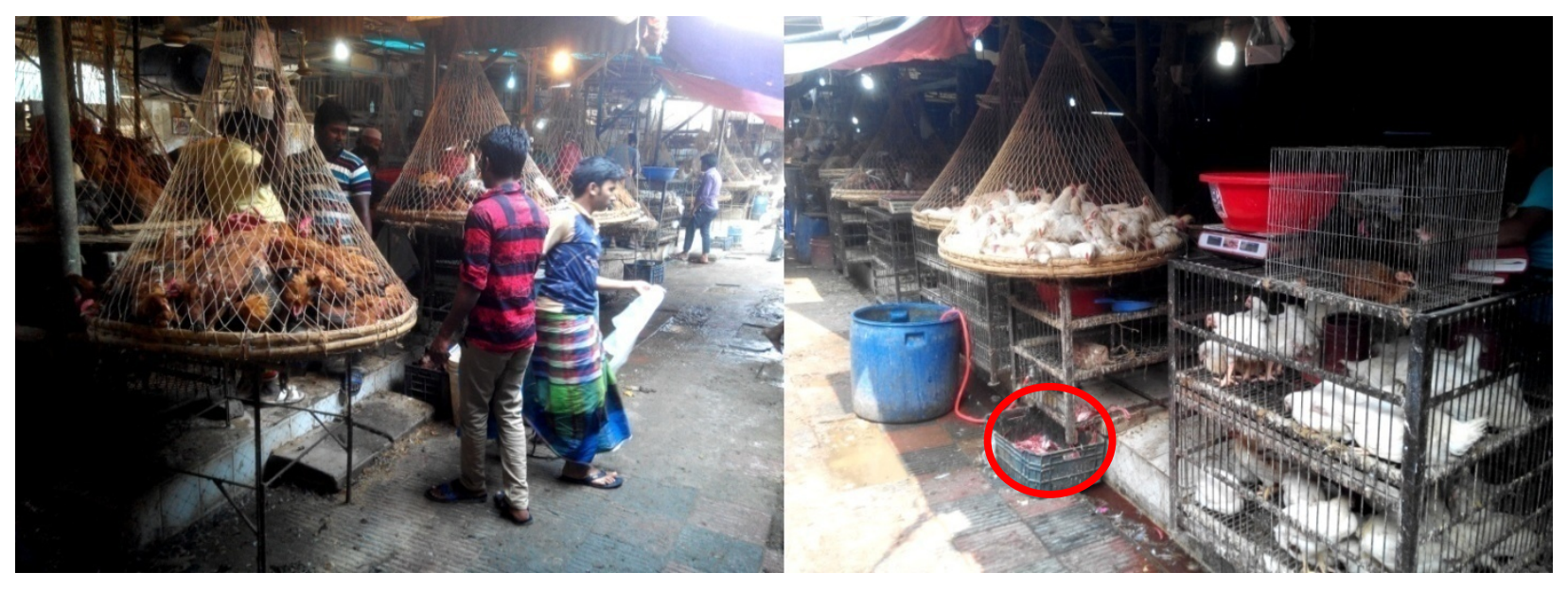

Figure 1: One urban live bird market in Dhaka, Bangladesh (poultry waste kept inside a basket; circled in red)

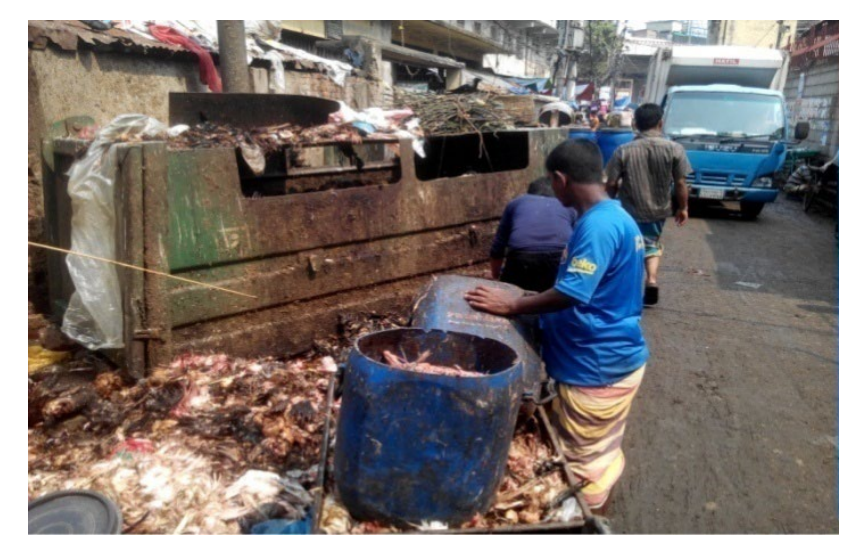

Figure 2: Waste disposal at the municipal bin in urban live bird markets in Dhaka, Bangladesh 


\section{References:}

Alam, M.-U., Winch PJ, Yeasmin F, Nizame FA, Saxton RE, Norman G, . . SP, L. (2017). Menstrual hygiene management among Bangladeshi adolescent schoolgirls and risk factors affecting school absence: results from a crosssectional survey. BMJ Open, 7. doi:10.1136/bmjopen-2016-015508

Ansarey, F. H. (2012). Prospects of poultry industry in Bangladesh. Paper presented at the Proceedings of the Seminar and Reception on Animal Husbandry Education and Profession in Bangladesh- A Journey of 50 Years, (AHEPB'12), Dhaka, Bangladesh.

Biran, A., Rabie, T., Schmidt, W., Juvekar, S., Hirve, S., \& Curtis, V. (2008). Comparing the performance of indicators of hand-washing practices in rural Indian households. Trop Med Int Health, 13(2), 278285. doi:10.1111/j.1365-3156.2007.02001.x

Blaak, H., van Hoek, A. H., Hamidjaja, R. A., van der Plaats, R. Q., Kerkhof-de Heer, L., de Roda Husman, A. M., \& Schets, F. M. (2015). Distribution, Numbers, and Diversity of ESBL-Producing E. coli in the Poultry Farm Environment. PLoS One, 10(8), e0135402. doi:10.1371/journal.pone.0135402

Braykov, N. P., Eisenberg, J. N., Grossman, M., Zhang, L., Vasco, K., Cevallos, W., . . Levy, K. (2016). Antibiotic Resistance in Animal and Environmental Samples Associated with Small-Scale Poultry Farming in Northwestern Ecuador. mSphere, 1(1). doi:10.1128/mSphere.00021-15

Brower, C. H., Mandal, S., Hayer, S., Sran, M., Zehra, A., Patel, S. J., . . Laxminarayan, R. (2017). The Prevalence of Extended-Spectrum Beta-Lactamase-Producing Multidrug-Resistant Escherichia Coli in Poultry Chickens and Variation According to Farming Practices in Punjab, India. Environ Health Perspect, 125(7), 077015. doi:10.1289/EHP292

Chowdhury, S. D. (2013). Family poultry production in Bangladesh: is it meaningful or an aimless journey? Worlds Poultry Science Journal, 69(3), 649-665. doi:10.1017/S0043933913000652

Collignon, P., Beggs, J. J., Walsh, T. R., Gandra, S., \& Laxminarayan, R. (2018). Anthropological and socioeconomic factors contributing to global antimicrobial resistance: a univariate and multivariable analysis. Lancet Planet Health, 2(9), e398-e405. doi:10.1016/S25425196(18)30186-4

Costa, P. M., Vaz-Pires, P., \& Bernardo, F. (2008). Antimicrobial resistance in Escherichia coli isolated in wastewater and sludge from poultry slaughterhouse wastewater plants. Journal of Environmental Health, 70(7), 40-45.

Curtis, V., Cousens, S., Mertens, T., Traore, E., Kanki, B., \& Diallo, I. (1993). Structured observations of hygiene behaviours in Burkina Faso: validity, variability, and utility. Bull World Health Organ, 71(1), 23-32.

Dinh, P. N., Long, H. T., Tien, N. T., Hien, N. T., Mai le, T. Q., Phong le, H., ... Response Network Avian Influenza Investigation Team in, V. (2006). Risk factors for human infection with avian influenza A H5N1, Vietnam, 2004. Emerg Infect Dis, 12(12), 1841-1847. doi:10.3201/eid1212.060829

Donkor, E. S., Newman, M. J., \& Yeboah-Manu, D. (2012). Epidemiological aspects of non-human antibiotic usage and resistance: implications for the control of antibiotic resistance in Ghana. Trop Med Int Health, 17(4), 462-468. doi:10.1111/j.1365-3156.2012.02955.x

Drankiewicz, D., \& Dundes, L. (2003). Handwashing among female college students. American Journal of Infection Control, 31(2), 67-71.

Ercumen, A., Pickering, A. J., Kwong, L. H., Arnold, B. F., Parvez, S. M., Alam, M., . . Colford, J. M. (2017). Animal Feces Contribute to Domestic Fecal Contamination: Evidence from E-coli Measured in Water, Hands, Food, Flies, and Soil in Bangladesh. Environmental Science \& Technology, 51(15), 8725-8734.

Fair, R. J., \& Tor, Y. (2014). Antibiotics and bacterial resistance in the 21st century. Perspect Medicin Chem, 6, 25-64. doi:10.4137/PMC.S14459 
Graham, J. P., Evans, S. L., Price, L. B., \& Silbergeld, E. K. (2009). Fate of antimicrobial-resistant enterococci and staphylococci and resistance determinants in stored poultry litter. Environ Res, 109(6), 682-689. doi:10.1016/j.envres.2009.05.005

Halder, A. K., Tronchet, C., Akhter, S., Bhuiya, A., Johnston, R., \& Luby, S. P. (2010). Observed hand cleanliness and other measures of handwashing behavior in rural Bangladesh. Bmc Public Health, 10.

Hasan, B., Faruque, R., Drobni, M., Waldenstrom, J., Sadique, A., Ahmed, K. U., . . Alam, M. (2011). High prevalence of antibiotic resistance in pathogenic Escherichia coli from large- and small-scale poultry farms in Bangladesh. Avian Dis, 55(4), 689-692. doi:10.1637/9686-021411-Reg.1

Hudson, M. A., Young, R. P., D'Urban Jackson, J., Orozco-terWengel, P., Martin, L., James, A., . . . Cunningham, A. A. (2016). Dynamics and genetics of a disease-driven species decline to near extinction: lessons for conservation. Sci Rep, 6, 30772. doi:10.1038/srep30772

Joardar, J. C., \& Rahman, M. M. (2018). Poultry feather waste management and effects on plant growth. International Journal of Recycling of Organic Waste in Agriculture, 7(3), 183-188. doi:10.1007/s40093-018-0204-z

K.Raha, S. (2000). Poultry Industry in Bangladesh: Present Status and Future Potential. Retrieved from https://bea-bd.org/site/images/pdf/084.pdf

Landers, T. F., Cohen, B., Wittum, T. E., \& Larson, E. L. (2012). A Review of Antibiotic Use in Food Animals: Perspective, Policy, and Potential. Public Health Reports, 127(1), 4-22.

Luby, S. P., Halder, A. K., Huda, T., Unicomb, L., \& Johnston, R. B. (2011). The effect of handwashing at recommended times with water alone and with soap on child diarrhea in rural Bangladesh: an observational study. PLoS Med, 8(6), e1001052. doi:10.1371/journal.pmed.1001052

ManunEbo, M., Cousens, S., Haggerty, P., Kalengaie, M., Ashworth, A., \& Kirkwood, B. (1997). Measuring hygiene practices: A comparison of questionnaires with direct observations in rural Zaire. Tropical Medicine \& International Health, 2(11), 1015-1021.

Marshall, B. M., \& Levy, S. B. (2011). Food Animals and Antimicrobials: Impacts on Human Health. Clinical Microbiology Reviews, 24(4), 718-+.

Munger, K., \& Harris, S. J. (1989). Effects of an Observer on Handwashing in a Public Restroom. Perceptual and Motor Skills, 69(3), 733-734. doi:DOI 10.2466/pms.1989.69.3.733

Nasreen, S., Khan, S. U., Luby, S. P., Gurley, E. S., Abedin, J., Zaman, R. U., . . Azziz-Baumgartner, E. (2015). Highly Pathogenic Avian Influenza A(H5N1) Virus Infection among Workers at Live Bird Markets, Bangladesh, 2009-2010. Emerging Infectious Diseases, 21(4), 629-637. doi:10.3201/eid2104.141281

Parvez, S. M., Azad, R., Rahman, M., Unicomb, L., Ram, P. K., Naser, A. M., . . Luby, S. P. (2018). Achieving optimal technology and behavioral uptake of single and combined interventions of water, sanitation hygiene and nutrition, in an efficacy trial (WASH benefits) in rural Bangladesh. Trials, 19(1), 358. doi:10.1186/s13063-018-2710-8

Peng, Z. B., Wu, P., Ge, L., Fielding, R., Cheng, X. W., Su, W. K., .. Yu, H. J. (2014). Rural Villagers and Urban Residents Exposure to Poultry in China. PLoS One, 9(4). doi:ARTN e9543010.1371/journal.pone.0095430

Price, L. B., Johnson, E., Vailes, R., \& Silbergeld, E. (2005). Fluoroquinolone-resistant Campylobacter isolates from conventional and antibiotic-free chicken products. Environ Health Perspect, 113(5), 557-560. doi:10.1289/ehp.7647

Raghunath, D. (2008). Emerging antibiotic resistance in bacteria with special reference to India. Journal of Biosciences, 33(4), 593-603. doi:10.1007/s12038-008-0077-9

Ram, P. K., Halder, A. K., Granger, S. P., Jones, T., Hall, P., Hitchcock, D., . . Luby, S. P. (2010). Is Structured Observation a Valid Technique to Measure Handwashing Behavior? Use of Acceleration Sensors Embedded in Soap to Assess Reactivity to Structured Observation. 
American Journal of Tropical Medicine and Hygiene, 83(5), 1070-1076.

doi:10.4269/ajtmh.2010.09.0763

Rimi, N. A., Sultana, R., Ishtiak-Ahmed, K., Khan, S. U., Sharker, M. A. Y., Zaman, R. U., . . Luby, S. P. (2014). Poultry Slaughtering Practices in Rural Communities of Bangladesh and Risk of Avian Influenza Transmission: A Qualitative Study. Ecohealth, 11(1), 83-93. doi:10.1007/s10393-0130885-8

Roess, A. A., Winch, P. J., Akhter, A., Afroz, D., Ali, N. A., Shah, R., . . Group, t. B. P. S. (2015). Household Animal and Human Medicine Use and Animal Husbandry Practices in Rural Bangladesh: Risk Factors for Emerging Zoonotic Disease and Antibiotic Resistance. Zoonoses and Public Health, 62(7), 569-578. doi:10.1111/zph.12186

Rousham, E. K., Islam, M. A., Masud, A.-A., Unicomb, L., Alam, M. U., Asaduzzaman, M., . . Rahman, M. (2018). Observations of human hygiene behaviours before and after exposure to poultry in Dhaka and rural Tangail district, Bangladesh (2017). Retrieved from: https://doi.org/10.5285/76f52a38-7a2c-49a3-b86f-cc40205459ef

Shanta, I. S., Hasnat, M. A., Zeidner, N., Gurley, E. S., Azziz-Baumgartner, E., Sharker, M. A. Y., . . . Luby, S. P. (2017). Raising Backyard Poultry in Rural Bangladesh: Financial and Nutritional Benefits, but Persistent Risky Practices. Transboundary and Emerging Diseases, 64(5), 1454-1464. doi:10.1111/tbed.12536

Silva, N. C. C., Guimaraes, F. F., Manzi, M. P., Budri, P. E., Gomez-Sanz, E., Benito, D., . . Torres, C. (2013). Molecular characterization and clonal diversity of methicillin-susceptible Staphylococcus aureus in milk of cows with mastitis in Brazil. Journal of Dairy Science, 96(11), 6856-6862. doi:10.3168/jds.2013-6719

Smith, T. C., Gebreyes, W. A., Abley, M. J., Harper, A. L., Forshey, B. M., Male, M. J., . . Davies, P. R. (2013). Methicillin-resistant Staphylococcus aureus in pigs and farm workers on conventional and antibiotic-free swine farms in the USA. PLoS One, 8(5), e63704. doi:10.1371/journal.pone.0063704

Stanton, B. F., Clemens, J. D., Aziz, K. M., \& Rahman, M. (1987). Twenty-four-hour recall, knowledgeattitude-practice questionnaires, and direct observations of sanitary practices: a comparative study. Bull World Health Organ, 65(2), 217-222.

Trust, W., CDC, U., \& Network, U. S. I. (2018). Initiatives for Addressing Antimicrobial Resistance in the Environment: Current Situation and Challenges. Retrieved from https://wellcome.ac.uk/sites/default/files/antimicrobial-resistance-environment-report.pdf

Unicomb, L., Horng, L., Alam, M. U., Halder, A. K., Shoab, A. K., Ghosh, P. K., . . Luby, S. P. (2018). Health-Care Facility Water, Sanitation, and Health-Care Waste Management Basic Service Levels in Bangladesh: Results from a Nation-Wide Survey. American Journal of Tropical Medicine and Hygiene, 99(4), 916-923. doi:10.4269/ajtmh.18-0133

Van Boeckel, T. P., Brower, C., Gilbert, M., Grenfell, B. T., Levin, S. A., Robinson, T. P., . . Laxminarayan, R. (2015). Global trends in antimicrobial use in food animals. Proceedings of the National Academy of Sciences of the United States of America, 112(18), 5649-5654. doi:10.1073/pnas.1503141112

Verraes, C., Van Boxstael, S., Van Meervenne, E., Van Coillie, E., Butaye, P., Catry, B., . . Herman, L. (2013). Antimicrobial resistance in the food chain: a review. Int J Environ Res Public Health, 10(7), 2643-2669. doi:10.3390/ijerph10072643

Wichaidit, W., Alam, M. U., Halder, A. K., Unicomb, L., Hamer, D. H., \& Ram, P. K. (2016). Availability and Quality of Emergency Obstetric and Newborn Care in Bangladesh. American Journal of Tropical Medicine and Hygiene, 95(2), 298-306. doi:10.4269/ajtmh.15-0350 
Woolhouse, M., Waugh, C., Perry, M. R., \& Nair, H. (2016). Global disease burden due to antibiotic resistance - state of the evidence. Journal of Global Health, 6(1). doi:UNSP 01030610.7189/jogh.06.010306

World's Poultry Science Association, B. B. (2017). 10th International Poultry Show and Seminar 2017. Paper presented at the 10th International Poultry Show and Seminar 2017, Dhaka, Bangladesh. https://wpsa-bb.com/keynote-paper

Zambrano, L. D., Levy, K., Menezes, N. P., \& Freeman, M. C. (2014). Human diarrhea infections associated with domestic animal husbandry: a systematic review and meta-analysis. Trans $R$ Soc Trop Med Hyg, 108(6), 313-325. doi:10.1093/trstmh/tru056

Zhou, L., Liao, Q. H., Dong, L. B., Huai, Y., Bai, T., Xiang, N. J., ... Yu, H. J. (2009). Risk Factors for Human Illness with Avian Influenza A (H5N1) Virus Infection in China. Journal of Infectious Diseases, 199(12), 1726-1734. doi:10.1086/599206

Zhu, Y. G., Johnson, T. A., Su, J. Q., Qiao, M., Guo, G. X., Stedtfeld, R. D., . . Tiedje, J. M. (2013). Diverse and abundant antibiotic resistance genes in Chinese swine farms. Proceedings of the National Academy of Sciences of the United States of America, 110(9), 3435-3440. doi:10.1073/pnas.1222743110 